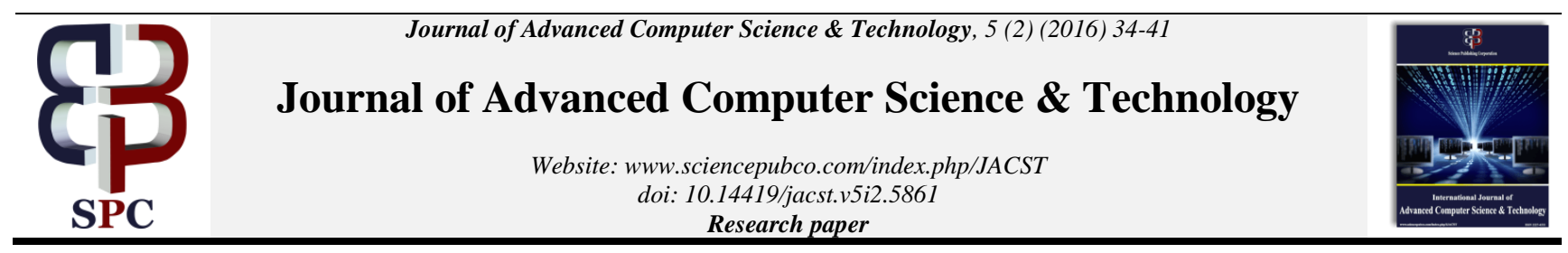

\title{
Performance trends for operational intelligence through value chain model
}

\author{
Rajeev Kaula * \\ Computer Information Systems Department Missouri State University 901 South National Ave. Springfield, MO 65897 \\ *Corresponding author E-mail: RajeevKaula@missouristate.edu
}

\begin{abstract}
Value chain is a successful management model for improving business competitiveness. A value chain based analytic approach facilitates meaningful grouping of business processes such that appropriate value from business operations can be derived. As organizations focus on competitive advantage and growth, a value chain derived operational intelligence provides insight to compete successfully in the marketplace. This paper outlines an approach to develop performance based value metrics in the form of analytic business rules for operational intelligence through the value chain model. The paper illustrates the concepts through a University value chain prototype which is implemented in Oracle's PL/SQL language.
\end{abstract}

Keywords: Business Intelligence; Business Process; Operational Intelligence; Business Process Intelligence; Business Rules.

\section{Introduction}

Business intelligence (BI) is a type of information system that generally analyzes large amounts of information to provide insight into business operations, identify new business opportunities, and deliver competitive advantage [7], [8], [16], [20]. Even though the role of $\mathrm{BI}$ in discovering new business opportunities has gained a lot of attention, the utilization of its concepts to enhance business processes and operational intelligence is a key factor in achieving business objectives [9], [10], [18], [19]. As an organization is a collection of business processes, improving business process performance through operational intelligence is essential for enhancing an organization's ability to achieve business objectives, besides facilitating competitive advantage.

One approach to generate insight often involves modeling of business information and performing analytics through a data warehouse in the form of star schema or its variants [2], [14], [15], [27], and [30]. Modeling of the data warehouse schema is accomplished through analysis of business operations [21] involving business activities or a business process. Now even though modeling of information for star schema is important as it allows an organization to make sense of data and generate the insight that is useful and relevant to the business process, such modeling is essentially a snapshot on some factors of a business process.

An alternative approach can be to outline business rules [12], [25] that indicate performance trends with respect to some performance criteria. Performance trends essentially is a way to determine the direction of performance in the form of whether certain dimensional factors bring an improvement or decline in business process performance with respect to some measure. Such an assessment provides a business with a more timely understanding of how the business process is performing. One way to express performance trends is through an adaptation of business rules referred as analytic business rules.

There have been attempts toward analysis of business operations (referred as process intelligence) in the form of process monitor- ing, process analysis, process discovery, conformance checking, prediction and optimizations [6], [11]. However these attempts are based on performance that is specific to individual business processes. Given the multitudes of business processes utilized by an organization, it is better to group business processes for operational analytics. Such grouping facilitates a broader set of performance metrics specifications. In this context the value chain model provides an appropriate model that aligns business processes with business goals for analytics and value generation.

Value chain is a management model for improving business competitiveness [3], [22], [23], [24]. Since the model sequences the primary and support activities to support business operations, it also provides fluidity in business operations from an analytical standpoint. A value chain based analytic approach facilitates meaningful grouping of business processes such that appropriate value from business operations can be derived.

This paper outlines an approach to develop performance trends through analytic business rules for operational intelligence through the value chain model. Since each value chain activity is a collection of business processes, performance trends for each value activity can be expressed by analytic business rules that are derived through a multidimensional model like star schema. The paper illustrates the concept through a prototype of a University value chain. Review of business process based operational intelligence is outlined now. Value chain concepts are outlined next from the perspective of process based operational intelligence, followed by a prototype of performance trends based on University value chain in the form of analytic business rules.

\section{Review of process based operational intelli- gence}

Business process intelligence analyzes business processes to ensure that their operational efficiency is consistent with their stated objectives. The goal is to optimize such processes for competitive performance. There have been three approaches towards utiliza- 
tion of BI towards business process based operational analytics. All three approaches focus on individual business process operations instead of ensuring or determining their value metrics from the perspective of a business value chain.

The first approach focuses on (i) using BI concepts toward dynamic process performance evaluation [5], [13], [28], or (ii) analyze event logs to improve the quality of business processes [1], or (iii) monitor process instances to inform users about unusual or undesired situations [11]. These approaches apply BI to individual business processes along with providing analytics associated with business process activities.

The second approach emphasizes analytics with selected business process activities within the modeling process [4]. It shows reference to analytic information during business process modeling as a way to incorporate BI. The approach is short on implementation details on how to perform analytics.

The third approach focuses on utilizing BI to reduce redundant specifications of recurrent business functions when modeling business processes [29]. It fosters reuse of business function specifications and helps to improve the quality

It represents all activities that a business undertakes to make a product or service from its conception to its end use and beyond.
Value chains can be split into primary value activities and support value activities. Each value chain activity is a collection of business processes. For instance one of the primary value activity in a manufacturing business is inbound logistics. Inbound logistics may consist of business processes such as inventory management and inbound freight logistics.

\section{Value chain for operational intelligence}

A value chain (shown in Fig. 1) is a chain of activities that a firm operating in a specific industry performs in order to deliver a valuable product or service to the market [23], [24]. It represents all activities that a business undertakes to make a product or service from its conception to its end use and beyond. Value chains can be split into primary value activities and support value activities. Each value chain activity is a collection of business processes. For instance one of the primary value activity in a manufacturing business is inbound logistics. Inbound logistics may consist of business processes such as inventory management and inbound freight logistics.

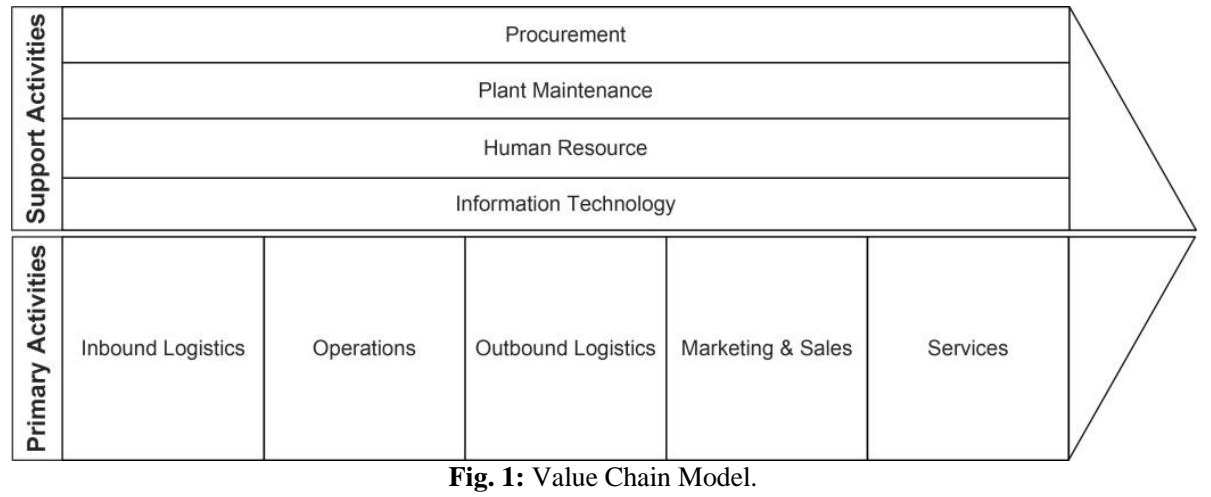

Value chains are utilized to improve business competitiveness by determining the value of each activity toward business success The two common methods of determining value are cost and differentiation. However, from a business intelligence perspective an alternative mechanism for determining value can be performance metrics that provides a measure of a value activity's success and value.

As a value chain model is based on the process view of an organization, the data generated by business processes within a value activity can be analyzed to identify the performance measure for the overall activity, and accordingly develop performance metrics to determine the value for such activity. For instance, inbound logistics that involves relationships with suppliers and includes all the activities required to receive, store, and disseminate raw mate- rials or product inputs includes business processes like inbound freight logistics, procure to pay, and so on. Once the dimensional data and performance measures for determining the value of inbound logistics is identified, a multidimensional model star schema can be developed to facilitate such analytics.

\section{University value chain for operational intel- ligence}

To illustrate the concept of utilizing value chain model for operational intelligence, a generic University value chain model is outlined in Fig. 2. The diagram only focuses on some of the student related primary value activities.

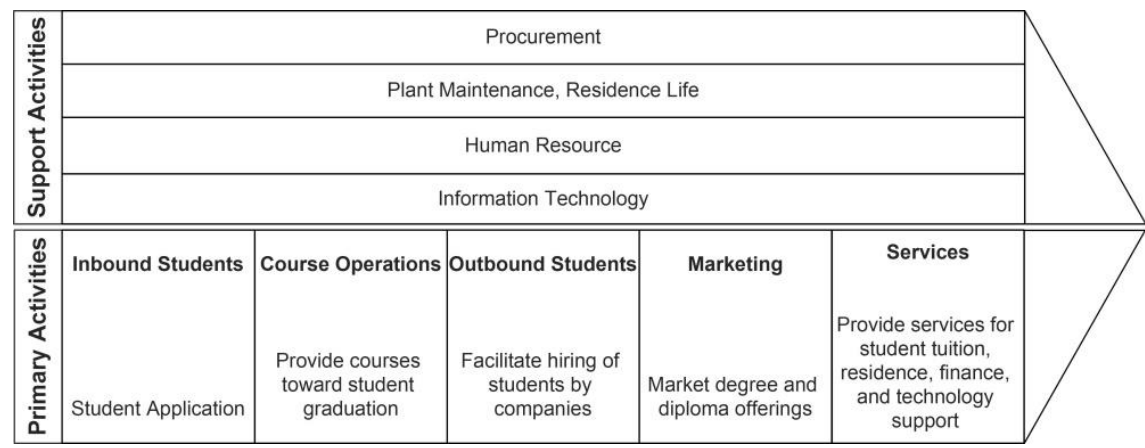

Fig. 2: University Value Chain Model.

In the figure "Inbound Students" pertains to activities associated with the recruitment of prospective students by the University. It includes processing of student applications. "Course Operations" includes all activities ranging from course registration, advising to student graduation. "Outbound Students" refers to University activities that facilitate companies to visit campus to interview and 
offer jobs to graduating students. "Marketing" are the efforts the University undertakes to promote their programs. "Services" are supplementary activities like financial aid, residence hall living, or computing support that facilitate proper living and timely graduation of students.

As each activity is a collection of business processes, a business process specific value chain model is shown in Fig. 3. In the figure, Inbound Students contains business processes like Campus Recruitment, Campus Visit, Student Orientation and Student Admission. The business processes in Course Operations range from Registration to Student Graduation. Outbound Students business processes range from Job Workshop to Career Placement. Market- ing contains business processes like College Fairs and Advertising Campaign. These business process pertain to the marketing of campus degree and diplomas. Services contains business processes pertaining to cashier services, residence life, financial aid, and technology support.

The business processes within a value activity are often sequenced in their operations as shown in Fig. 4. For instance, in the figure, business process sequence for Inbound Students, Course Operations, and Outbound Students value activities are shown. In general such logical arrangements facilitate understanding of the workflow sequence within a value activity.

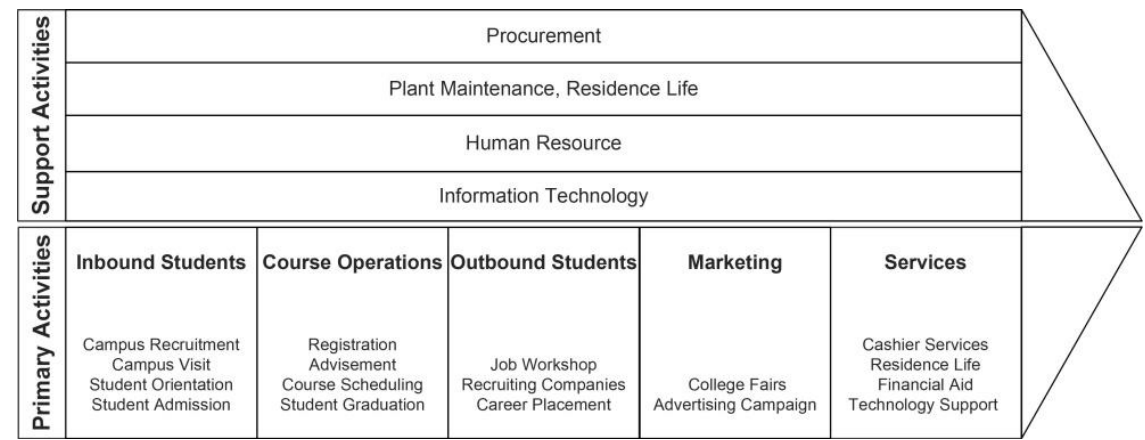

Fig. 3: University Value Chain Model with Business Processes.

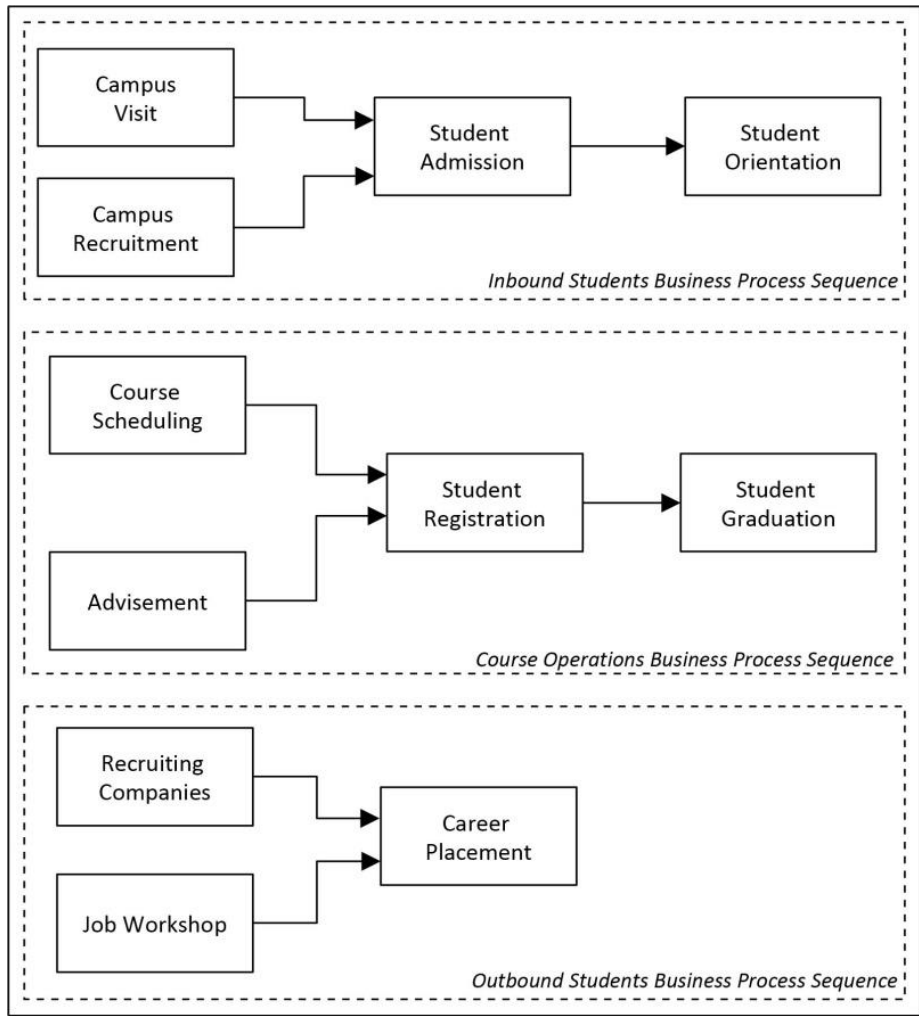

Fig. 4: Value Chain Activity Business Process Sequence.

\section{Transform value chain activity into analytic business rules}

Value chains can assist in the development of performance trends expressed as analytic business rules to assess whether the value chain activities are aligned with business objectives. To accomplish the development of analytic business rules and associated performance trends (i) dimensional modeling on the group of business processes within a value chain activity in the form of star schema is performed, (ii) followed by the transformation of star schema into relevant performance trends expressed as analytic business rules, and (iii) finally the analytic business rules based appropriate analytic triggers are set to ensure the success of value chain activity.

\subsection{Star schema prototype for value chain activity}

To ensure that primary value activities are achieving their value and success, one can develop a star schema for each such value activity. So for example, Inbound Students value activity value can be enhanced or have more value if more students get accepted. The higher the student acceptance, the better the overall success of the Inbound Students value activity. So instead of determining what factors contribute to a specific student acceptance count for value activity optimum success, an alternative approach could be to determine the impact of certain dimensional factors towards 
student acceptance, and then determining if the student acceptance trends up or trend down or stays flat over time. This approach utilizes appropriate or relevant dimensions from the business processes within Inbound Students. The dimensional factors that impact student acceptance count trend up or trend down or stay flat provide the relationships that later defines the analytic business rule. Fig. 5 shows some of the dimension entities associated with the business processes within Inbound Students value activity.

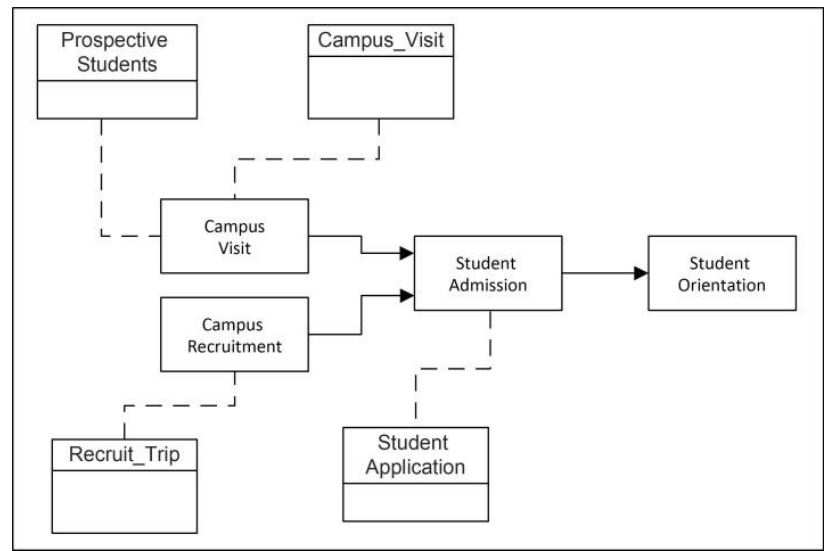

Fig. 5: Inbound Students Value Activity Dimension Entity Types.

These dimension entities are then assembled in a star schema is shown in Fig. 6 with performance measure on student acceptance count. Since performance trends are time based, time dimension is also added to the schema. The analysis of student acceptance count performance trend will indicate the factors that contribute to an improvement or decline in acceptance over time with regard to Inbound Students activity. The relationship among the dimension attributes defines the value driven analytic business rule. The dimensions structure is not hierarchical. Even though in general a fact less star schema is utilized for observing trends, but having a performance measure ensures that trends pertain to dimensions that are linked to success based on some key fact measures.

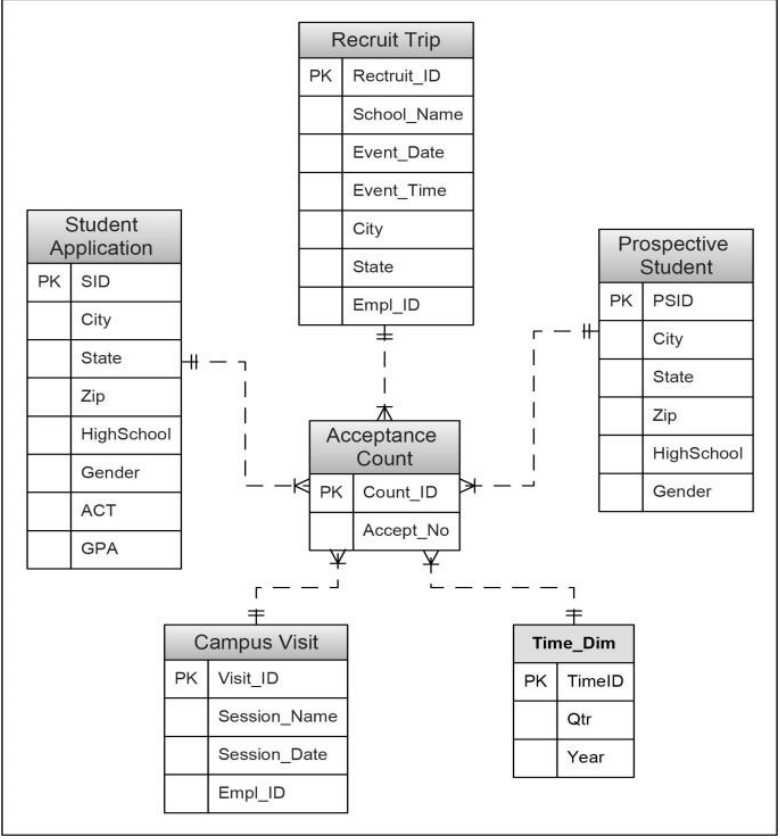

Fig. 6: Inbound Students Value Activity Star Schema.

The table structure with sample data for the above dimensions and fact measures are listed from Table 1 through Table 6 as follows:

\subsection{Transform star schema into analytic business rules}

Once the star schema is queried, the specific dimension data elements (or factors) that affect student acceptance can be identified. The relationship of these dimension data elements (or factors) with fact measure is then expressed through analytic business rules. The logic of developing business rules based on star schema query is shown in Fig. 7.

Table 1: Student Application

\begin{tabular}{|c|c|c|c|c|c|c|c|}
\hline SID & City & State & ZIP & High_School & Gender & ACT & GPA \\
\hline 1 & Springfield & MO & 65802 & Central High & M & 25 & 4.5 \\
\hline 2 & Springfield & MO & 65807 & Kickapoo High & $\mathrm{F}$ & 26 & 5 \\
\hline 3 & Springfield & MO & 64101 & Central High & M & 23 & 4 \\
\hline 4 & Springfield & MO & 64102 & Central High & M & 28 & 3.8 \\
\hline 5 & Springfield & MO & 65802 & Central High & M & 21 & 3 \\
\hline 6 & Springfield & MO & 65804 & Kickapoo High & F & 29 & 5 \\
\hline 7 & Kansas City & MO & 64102 & Lincoln High & $\mathrm{F}$ & 20 & 3.2 \\
\hline 8 & Overland Park & KS & 66204 & Shawnee Mission & $\mathrm{F}$ & 28 & 4.2 \\
\hline 9 & Springfield & $\mathrm{KS}$ & 66204 & Central High & M & 29 & 4.9 \\
\hline 10 & Overland Park & KS & 66205 & Blue Valley & $\mathrm{F}$ & 20 & 2.5 \\
\hline 11 & Springfield & MO & 65802 & Central High & M & 30 & 4.5 \\
\hline 12 & Springfield & MO & 65807 & Kickapoo High & $\mathrm{F}$ & 27 & 5 \\
\hline 13 & Kansas City & MO & 64101 & Central High & M & 27 & 4 \\
\hline 14 & Springfield & MO & 64102 & Central High & M & 26 & 3.8 \\
\hline 15 & Springfield & MO & 65802 & Central High & M & 22 & 3 \\
\hline 16 & Springfield & MO & 65804 & Kickapoo High & $\mathrm{F}$ & 30 & 5 \\
\hline 17 & Kansas City & MO & 64102 & Lincoln High & F & 22 & 3.2 \\
\hline
\end{tabular}




\begin{tabular}{|c|c|c|c|c|c|c|c|}
\hline 18 & Springfield & KS & 66204 & Central High & $\mathrm{F}$ & 27 & 4.2 \\
\hline 19 & Springfield & KS & 66204 & Central High & M & 30 & 4.9 \\
\hline
\end{tabular}

Table 2: Prospective Student

\begin{tabular}{|c|c|c|c|c|c|}
\hline PSID & City & State & ZIP & High_School & Gender \\
\hline 1 & Springfield & MO & 65802 & Central High & M \\
\hline 2 & Springfield & MO & 65807 & Kickapoo High & $\mathrm{F}$ \\
\hline 3 & Kansas City & MO & 64101 & Lincoln High & M \\
\hline 4 & Kansas City & MO & 64102 & Raytown High & M \\
\hline 5 & Springfield & MO & 65802 & Central High & M \\
\hline 6 & Springfield & MO & 65804 & Kickapoo High & $\mathrm{F}$ \\
\hline 7 & Kansas City & MO & 64102 & Lincoln High & $\mathrm{F}$ \\
\hline 8 & Overland Park & $\mathrm{KS}$ & 66204 & Shawnee Mission & $\mathrm{F}$ \\
\hline 10 & Overland Park & $\mathrm{KS}$ & 66205 & Blue Valley & $\mathrm{F}$ \\
\hline
\end{tabular}

Table 3: Campus Visit

\begin{tabular}{|c|c|c|c|}
\hline Visit_ID & Session_Name & Session_Date_Time & Empl_ID \\
\hline 1 & Financial Aid & 3-Feb-14 & 2 \\
\hline 2 & Overview & 3-Feb-14 & 1 \\
\hline 3 & Career Service & $3-F e b-14$ & 3 \\
\hline 5 & Financial Aid & 3-Mar-14 & 2 \\
\hline 6 & Overview & 3-Mar-14 & 1 \\
\hline 7 & Career Service & 3-Mar-14 & 3 \\
\hline 8 & Campus Tour & 3-Mar-14 & 4 \\
\hline 9 & Online Tour & & \\
\hline
\end{tabular}

Table 4: Recruit Trip

\begin{tabular}{|c|c|c|c|c|c|c|}
\hline Recruit_ID & School_Name & Event_Date & Event_Time & City & State & Empl_ID \\
\hline 1 & UMKC Career Fest & 25-Sep-13 & 1-Feb-15 & Kansas City & MO & 1 \\
\hline 2 & UMKC Career Fest & 25-Oct-13 & $1-F e b-15$ & Kansas City & MO & 1 \\
\hline 3 & Central High & $25-F e b-14$ & $1-F e b-15$ & Springfield & MO & 2 \\
\hline 4 & Kickapoo High & 20-Feb-14 & $1-F e b-15$ & Springfield & MO & 2 \\
\hline 5 & MSU Career Fest & 25-Oct-13 & $1-F e b-15$ & Springfield & MO & 2 \\
\hline 6 & MSU Online & & & Springfield & MO & \\
\hline
\end{tabular}

Table 5: Time_Dim

\begin{tabular}{lll}
\hline TimeID & Semester & Year \\
\hline 1 & Spring & 2012 \\
2 & Fall & 2012 \\
3 & Spring & 2013 \\
4 & Fall & 2013 \\
\hline
\end{tabular}




\begin{tabular}{lll}
\hline 5 & Spring & 2014 \\
6 & Fall & 2014 \\
\hline
\end{tabular}

Table 6: Student Status

\begin{tabular}{|c|c|c|c|c|c|c|}
\hline \\
\hline Status_ID & Accept_No & SID & PSID & Recruit_ID & Visit_ID & Time_ID \\
\hline 1 & 50 & 1 & 1 & 6 & 9 & 1 \\
\hline 2 & 60 & 2 & 2 & 4 & 2 & 2 \\
\hline 3 & 20 & 3 & 3 & 6 & 9 & 3 \\
\hline 4 & 10 & 4 & 4 & 2 & 8 & 4 \\
\hline 5 & 15 & 5 & 5 & 6 & 9 & 5 \\
\hline 6 & 20 & 6 & 6 & 6 & 2 & 6 \\
\hline 7 & 40 & 7 & 7 & 6 & 9 & 1 \\
\hline 8 & 25 & 8 & 8 & 6 & 9 & 2 \\
\hline 9 & 35 & 9 & 9 & 2 & 3 & 3 \\
\hline 10 & 40 & 10 & 10 & 6 & 9 & 4 \\
\hline 11 & 20 & 11 & 1 & 3 & 9 & 5 \\
\hline 12 & 15 & 12 & 3 & 4 & 9 & 6 \\
\hline 13 & 10 & 13 & 5 & 2 & 9 & 1 \\
\hline 14 & 10 & 14 & 7 & 2 & 9 & 2 \\
\hline 15 & 12 & 15 & 9 & 5 & 9 & 3 \\
\hline 16 & 20 & 16 & 2 & 5 & 9 & 4 \\
\hline 17 & 25 & 17 & 3 & 1 & 9 & 5 \\
\hline 18 & 30 & 18 & 5 & 1 & 9 & 6 \\
\hline 19 & 10 & 19 & 6 & 2 & 9 & 5 \\
\hline 20 & 10 & 20 & 7 & 2 & 9 & 6 \\
\hline
\end{tabular}

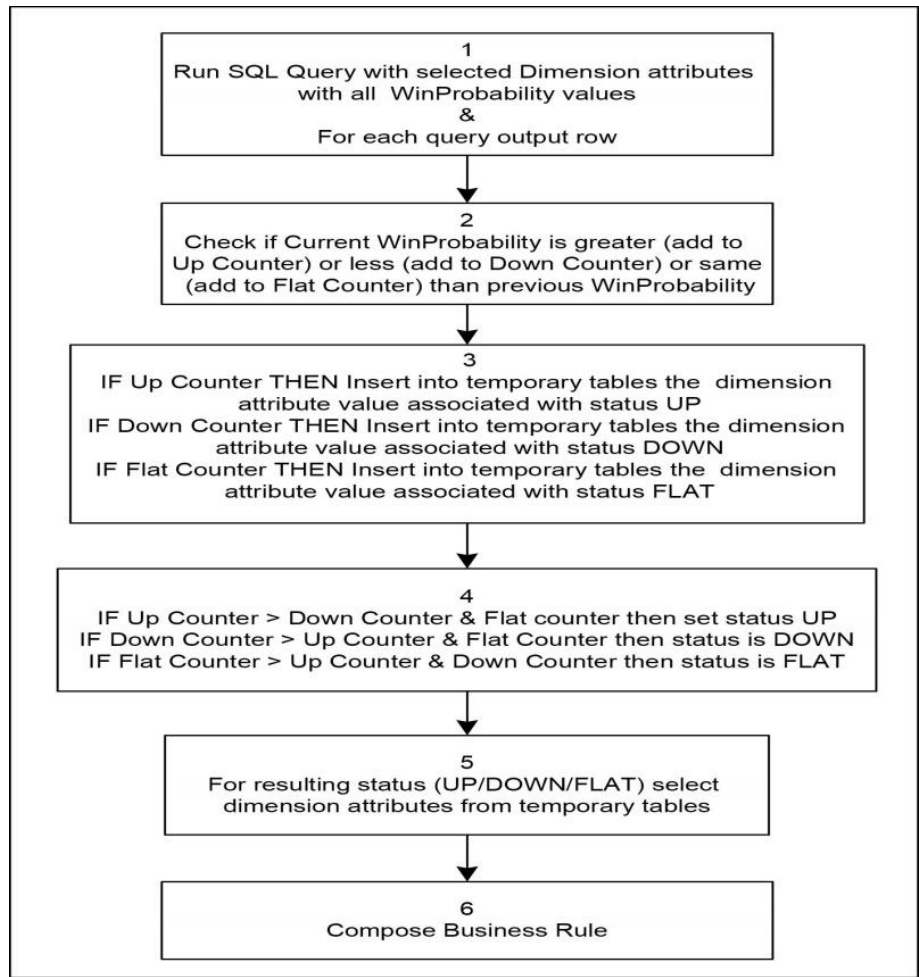

Fig. 7: Analytic Business Rule Logic 
The logic is implemented through a PL/SQL database procedure. To facilitate processing separate temporary tables were created for each query attribute to record the impact of attribute value for each type of trend. The implementation is PC based. Key features of the logic are as follows:

1) SQL query (part of logic step 1) is developed. For example, the following query lists dimension attributes associated with count of students accepted.

select count_id,accept_no,student_app.high_school as highschool, act,campus_visit.session_name as session-

name,recruit_trip.school_name, time_dim.semester,

time_dim.year

from acceptance_count, student_app, pros_student, campus_visit, recruit_trip,time_dim

where acceptance_count.sid = student_app.sid and

acceptance_count.psid $=$ pros_student.psid and

acceptance_count.recruit_id = recruit_trip.RECRUIT_ID and

acceptance_count.VISIT_ID = campus_visit.VISIT_ID and

acceptance_count.timeid $=$ time_dim.timeid

order by count_id;

2) Once the query is executed, the procedure checks for each query output row the following: (a) if accept_no in current query output row is greater than previous row accept_no, then adds 1 to a up counter and insert into temporary tables created for each dimension attribute in the select clause; (b) if accept_no in current query output row is less than previous row accept no, then adds 1 to a down counter and insert into temporary tables created for each dimension attribute in the select clause; and (c) if accept_no in current query output row is same as previous row accept_no, then adds 1 to a flat counter and insert into temporary tables created for each dimension attribute in the select clause. (Logic step 2 and $3)$.

3) After the query is processed, perform one of the following: (a) check if up counter is greater than down counter and flat counter. If true then status is UP and select dimension attributes associated with up counter from temporary tables; (b) check if down counter is greater than up counter and flat counter. If true then status is Down and select dimension attributes associated with down counter from temporary tables; and (b) check if flat counter is greater than up counter and down counter. If true then status is Flat and select dimension attributes associated with flat counter from temporary tables. (Logic step $4 \& 5$ )

4) Compose business rule that lists conclusions from step 3 , wherein the dimension attributes selected are part of the IF clause, while the associated trend status is part of the THEN clause. (Logic step 6)

Now, once the dimension factors that influence the student acceptance performance trend have been identified, the relationship among the dimension factor values and the performance trend can be expressed as an analytic business rule wherein the IF constraint represents the dimensional factor values, while the THEN action represents the performance value. The following is an instance of an analytic business rule resulting from the execution of the PL/SQL procedure.

IF

High School $=$ Central High AND

ACT score $=29$ AND

Campus Visit Session = Online Tour AND

Recruit Trip School = MSU Online AND

Time $=($ spring or fall $)$

THEN Value Activity Performance Trend is UP

The above analytic business rule consequently emphasizes that the value activity performance with respect to the number of students accepted is on a upward trend. Some of the factors that contribute towards achieving the up trend appear in the IF clause of the business rule.

\subsection{Develop value chain activity triggers}

Once the business rules have been defined, business intelligence based triggers for the value chain activity can be developed. In this metric, the dimension factor values can be used as a gauge to ensure high student acceptance. Generally business intelligence applications utilize dashboards to show key performance indicators (KPI) that are relevant to a particular objective or a business process [17], [26]. These KPIs are often tied to business metrics. In this context, a KPI for the value chain activity can be developed that focus on factors that ensures continued student acceptance by turning the student interests and application along with campus visits into more acceptance based on the business rule specification. The KPI can show how the changes in the business rules specified dimension factor values are influencing the student acceptance chances. In other words, the dashboard can track the IF constraints values, which based on the business rules indicate more student acceptance.

Once the value metric is developed, the business process sequence within the value chain activity can assist in identifying the business process activity that will raise alert with respect to business triggers to monitor specific information content. For example if there are less visitors to online Web site, steps may be taken to improve the Web site or its search to enhance student acceptance. Similarly other triggers can be established that will check on information and raise alert as needed (for example triggers to alert if less interest among students from Central High).

\section{Conclusion}

The value chain model of an organization can be a meaningful way to facilitate analysis of business processes and operational intelligence. As business intelligence focuses on improving decision making within an organization, presenting actionable information to the right people at the right time improves the quality and timeliness of decisions with respect to the value chain activity. A key aspects of value chain analytics is the alignment of performance based value metrics across a group of business processes. Even though operational intelligence is generally associated with individual business processes, the paper shows value chains provide an alternative approach to gain insight into successful business operations. Further research is underway to (i) develop more complex performance trends value metrics, (ii) explore association of value metrics with value chain activity transactional working, and (iii) develop dimensional model that incorporate business process sequence for metrics specification.

\section{References}

[1] W. M. P. van der Aalst, H. A. Reijers, A. J. M. M. Weijters, B. F. van Dongen, A. K. de Medeiros Alves, M. Song, and H. M. W. Verbeek, "Business process mining: An industrial application," Information Systems, vol. 32, no. 1, 2007, pp. 713-732. http://dx.doi.org/10.1016/j.is.2006.05.003.

[2] R. Agrawal, A. Gupta, and S. Sarawagi, "Modeling Multidimensional Databases," Proceedings of the Thirteenth International Conference on Data Engineering, Birmingham, UK, 1997, pp. 232 243. http://dx.doi.org/10.1109/icde.1997.581777.

[3] D. Barnes, Understanding Business Processes, New York: Routledge, 2001.

[4] T. Bucher, A. Gericke, and S. Sigg, "Process-centric business intelligence", Business Process Management Journal, vol. 15, no. 3, 2009 , pp $408 \quad 429$ http://dx.doi.org/10.1108/14637150910960648

[5] M. Castellanos, F. Casati, M. Sayal, and U. Dayal, "Challenges in business process analysis and optimization," in C. Bussler \& M. C. Shan (editors), Technologies for E-Services, $6^{\text {th }}$ International Work- 
shop, TES 2005, Trondheim, Norway, Revised in Lecture Notes in Computer Science, vol. 3811, 2005, pp. 1- 10.

[6] M. Castellanos, A. de Medeiros, J. Mendling, B. Weber, and A. Weijters, "Business Process Intelligence," in J. Cardoso and W. van der Aalst (editors) Handbook of Research on Business Process Modeling, Hershey: IGI Publishing, 2009, pp. 456-480. http://dx.doi.org/10.4018/978-1-60566-288-6.ch021.

[7] W. F. Cody, J. T. Kreulen, V. Krishna, and W. S Spangler, "The integration of business intelligence and knowledge management," IBM Systems Journal, vol. 41, no. 4, 2002, pp. 697-713. http://dx.doi.org/10.1147/sj.414.0697.

[8] U. Dayal, K. Wilkinson, A. Simitsis, and M. Castellanos, "Business Processes Meet Operational Business Intelligence," Bulletin of the Technical Committee on Data Engineering, vol. 32, no. 3, 2009, pp. $35-41$.

[9] M. Z. Elbashira, P. A. Collierb, and M. J. Davernb, "Measuring the effects of business intelligence systems: The relationship between business process and organizational performance," International Journal of Accounting Information Systems, vol. 9, no. 3, 2008, pp. 135-153. http://dx.doi.org/10.1016/j.accinf.2008.03.001.

[10] M. Golfarelli, S. Rizzi, and I. Cella, "Beyond data warehousing: what's next in business intelligence?" Proceedings of the 7th ACM international workshop on Data warehousing and OLAP, Washington, DC, USA, 2004, pp. 1-6. http://dx.doi.org/10.1145/1031763.1031765.

[11] D. Grigoria, F. Casatib, M. Castellanosb, U. Dayal, M. Sayalb, M. Shanb "Business Process Intelligence" Computers in Industry, vol. 53, no. 3, 2004, pp. 321-343. http://dx.doi.org/10.1016/j.compind.2003.10.007.

[12] B.V. Halle, Business Rules Applied, New York, NY: John Wiley \& Sons, 2002.

[13] R. Kaula, "Business Intelligence Process Metrics Specification: An Information Flow Approach," International Journal of Computers and Their Applications, vol. 19, no. 4, 2012, pp. 262-272.

[14] R. Kimball and M. Ross, the Data Warehouse Toolkit: The Complete Guide to Dimensional Modeling, New York: John Wiley \& Sons, 2002.

[15] R. Kimball, M. Ross, W. Thornthwaite, J. Mundy, and B. Becker, The Data Warehouse Lifecycle Toolkit, New York: John Wiley and Sons, 2008.

[16] R. Kimball and M. Ross, The Kimball Group Reader: Relentlessly Practical Tools for Data Warehousing and Business Intelligence, New York: Wiley Publishing, 2010.

[17] D. Loshin, Business Intelligence: The Savvy Manager's Guide, San Francisco: Morgan Kaufman, 2013.

[18] O. Marjanovic, "The Next Stage of Operational Business Intelligence: Creating New Challenges for Business Process Management," Proceedings of the 40th Annual Hawaii International Conference on System Sciences, Honolulu, HI, USA, 2007, pp. 215c215c. http://dx.doi.org/10.1109/hicss.2007.551.

[19] O. Marjanovic, "Business Value Creation through Business Processes Management and Operational Business Intelligence Integration," 43rd Hawaii International Conference on System Sciences (HICSS), Honolulu, HI, USA, 2010, pp. 1-10. http://dx.doi.org/10.1109/hicss.2010.89.

[20] C. M. Olszak and E. Ziemba, "Approach to Building and Implementing Business Intelligence Systems," Interdisciplinary Journal of Information, Knowledge, and Management, vol. 2, 2007, pp. 135-148.

[21] P. Ponniah, Data Warehousing Fundamentals for IT Professionals (2nd Edition), New York: John Wiley \& Sons, 2010. http://dx.doi.org/10.1002/9780470604137.

[22] M. E. Porter, "How Competitive Forces Shape Strategy," Harvard Business Review, March-April 1979, pp. 137.

[23] M. E. Porter, Competitive Advantage: Creating and Sustaining Superior Performance, New York: Simon and Schuster, 1985.

[24] M. E. Porter, "The Five Competitive Forces that Shape Strategy," Harvard Business Review, January 2008, pp. 86-104.

[25] R. Ross, Principles of the Business Rule Approach, Boston: Addison-Wesley, 2003.

[26] R. Sharda, D. Dalen, and E. Turban, Business Intelligence: A Managerial Perspective on Analytics, Upper Saddle River: PrenticeHall, 2013

[27] A. Sen and A. Sinha, "A comparison of data warehousing methodologies," Communications of the ACM, vol. 48, no. 3, 2005, pp. 79-84. http://dx.doi.org/10.1145/1047671.1047673.

[28] W. Tan, J.W. Shen, L. Xu, B. Zhou, L. Li “A Business Process Intelligence System for Enterprise Process Performance Management" IEEE Transactions on Systems, Man, and Cybernetics, vol.
38, no. 6, 2008, pp. 745-756 http://dx.doi.org/10.1109/TSMCC.2008.2001571.

[29] L. H. Thom, M. Reichert, C. M. Chiao, C. Iochpe and G. N. Hess "Inventing Less, Reusing More, and Adding Intelligence to Business Process Modeling” in S.S. Bhowmick, J. Küng, R. Wagner (editors), Database and Expert Systems Applications: Book Series Title: Lecture Notes in Computer Science, vol. 5181, 2008, pp. 837-850. http://dx.doi.org/10.1007/978-3-540-85654-2 75.

[30] R. Wrembel, and C. Koncilia, Data warehouses and OLAP: concepts, architectures, and solutions. Hershey: Idea Group Inc., 2007. http://dx.doi.org/10.4018/978-1-59904-364-7. 